\title{
A Good Lifestyle to Avoid Cardiovascular Disease
}

\author{
Dr. Muhammad Alnawa ${ }^{1 *}$, Dr. Mohamad Alfarouh ${ }^{2}$
}

${ }^{T}$ Consultant Emergency Medicine, PHCC, Doha, Qatar

${ }^{2}$ Specialist Internal Medicine, PHCC, Doha, Qatar

DOI: $10.36347 /$ sjams.2020.v08i11.014

| Received: 01.11.2020 | Accepted: 09.11.2020 | Published: 13.11.2020

*Corresponding author: Dr. Muhammad Alnawa

\section{Abstract}

Original Research Article

Background: Healthy lifestyle can avoid several problems related to our health and can also avoid several known diseases such as Cardiovascular diseases. In order to adopt a healthy lifestyle we need to adopt healthy habits such as eating a customized diet as per your daily routine and health, exercising regularly depending on the body weight goals to keep your body fit with minimal fat, and avoid eating food that contain high cholesterol such as beef, and quit smoking which would remarkably minimize the chance of cardiovascular diseases by managing and regulating the cholesterol levels, blood pressure, and other predisposing factors. Limited data are available about the consequences of multiple lifestyle factors that directly or indirectly affects the cardiovascular diseases. Method: We have considered the study to check the impact of change in lifestyle of those having cardiovascular disease and those who have never suffered with such diseases. The data were analyzed to associate CVD patients with corresponding normal individuals. Patient pairing was accomplished on one to one ground with reference to their age, sex, education and economic status. There was a total trial size of 162. A survey questionnaire system was prepared to understand lifestyle behavior, including questions on health habits, work engagement, locus of control. The recording of their reaction was analyzed. The higher the ratings, the more the unhealthy lifestyle is, while the balanced lifestyle is designated by low scores. We carried out qualitative and quantitative assessments. The hypothesis originated was that "Patients of cardiovascular diseases (CVD) will have a higher lifestyle score relative to matched non-CVD individuals".

Keywords: Cardiovascular Disease, Healthy Lifestyle, Healthy Diet, Health Habit Pattern Locus of Control.

Copyright $\odot 2020$ The Author(s): This is an open-access article distributed under the terms of the Creative Commons Attribution 4.0 International License (CC BY-NC 4.0) which permits unrestricted use, distribution, and reproduction in any medium for non-commercial use provided the original author and source are credited.

\section{INTRODUCTION}

Cardiovascular disease (CVD) has a very high risk of death and is known to be the primary cause of human morbidity, mortality, and disability irrespective of age sex, or race. The World Heart Federation states that one-third of the adults above the age of 25 suffer from cardiovascular diseases globally [1]. Every year over 17.5 million people die from cardiovascular disease worldwide which contributes to 30 percent of the annual death [2]. With the advancement of medical technology, the prospects of recovery of cardiovascular diseases have been significantly improved contributing to a decline in the fatality rate. However, this fatality rate in developing countries due to heart diseases is elevating mainly due to unhealthy lifestyle habits and environmental factors. The factors that impact the health and wellbeing of our heart are:

\section{LIFESTYLE RISK FACTORS OF CARDIOVASCULAR DISEASES SMOKING}

Cigarette smoking can elevate blood pressure and thus increase the chance of having a heart attack and stroke. When we compared the risk of cardiovascular diseases in both smokers and nonsmokers, we found out that the risk of CVD for smokers increases 1.6 fold [3]. A report from the Asia Pacific Cohort Studies Collaboration states that the risk of developing ischemic heart disease for smokers is 27 percent more as compared to non-smokers, 9 percent more seemingly for hemorrhagic stroke, 4.5 times more seemingly for hypertension, and 16 times more seemingly for hyperlipidemia [4].

\section{DIET}

Diet plays an important role in the occurrence and prevention of cardiovascular diseases. Irregular blood lipid levels which can be caused due to heavy consumption of fats carbohydrates and proteins are shown to have a strong correlation with the risk of heart diseases [5]. High dietary saturated fats contributes to the high levels of serum cholesterol, whereas unsaturated fats contained in vegetables, fish, seeds etc are important for the heart health as these fatty acid contain essential omega- 3 and omega- 6 fatty acids that 
are crucial to the heart and cannot be generated by the body. .

Another important risk factor of cardiovascular disease is hypertension which is partly due to salt intake. Excessive sodium in the diet can be very unfavorable for the cardiovascular system. According to the recommendation of WHO a daily intake of salt should be less than $5 \mathrm{~g}$ [6]. The unhealthy diet elevates the risk of hypercholesterolemia, hypertension, and diabetes which are the risk factors of heart diseases.

\section{EXERCISE}

Exercise can control a variety of regulatory peptides in the cardiovascular system and can reduce Creactive protein levels and slow down the development of cardiovascular diseases [7]. Exercise can lower body fat levels and enhances insulin sensitivity [8]. Executing a long-term exercise practice is a constructive method to lower CRP and both help in preventing cardiovascular diseases. Milani and his colleagues compared the result of cardiovascular rehabilitation training for three months in 235 coronary heart disease patients in which 42 patients have no rehabilitation therapy. The results exhibit that the body fat index, motility, and other risk factors of CVD were remarkably improved in the rehabilitated group [9].

\section{POLLUTION CONTROL}

It has been proposed that environmental pollution is the greater source of congenital heart diseases than the genetic factor. The developing fetus is also affected by environmental pollution during pregnancy and eventually lead to congenital heart diseases. Although the epidemiological verification is limited and the conflict remains, the Latest studies have exhibited that maternal exposure to pollution may also contribute to causing congenital anomalies, specifically congenital heart diseases [10]. The effect of environmental pollution has been examined in 45 heart disease patients in an area of Helsinki, Finland [11]. The patients in the trial rapidly reduce the amount of blood flow into the heart after inhaling polluted air for just two days. Although these patients show no sign of pain concerning this change in heart function it was a sign of heart disease progression.

\section{METHOD}

In our current study we only include male patients. 81 male CVD patients volunteered to participate in the research and so we find 81 matched normal individuals with no sign of any potential disease and the matching was done on the basis of their age, education, occupation, their family size and their economic status. Normal individuals were chosen after the complete medical examination by the physician who designate them as disease free individuals since they were not experiencing any illness. We asked both patients and normal individuals to fulfill the systemic procedure of the research which are mentioned below:
Age: $30-60$

Education: at least 10th grade passed

Occupation: employed

Family size: elementary family having a wife and children and joint family having a wife children and parents.

Economic status: financially stable

We collect the data using the following steps and techniques.

- The Personal information sheet: The personal information of both patients and normal individuals are collected in this data sheets which consist of 14 elements assembled to obtain the general details on age, education, occupation, family size and economic status.

- Interview sessions: interview sessions are conducted in a specific criteria with both patients and normal individuals in order to assess their lifestyle behaviors based on functional concept of lifestyle. These sessions are based on 3 sub-parts according to which questions are prepared in advance.

These 3 sub-parts are mentioned below,

1. Health habit pattern: It includes the details on sleeping pattern, eating pattern, physical activity and exercise routine, and alcohol and tobacco consumption. The recording of their reaction is analyzed. A five-point rating system i.e. always, often, sometimes, rarely and never is used to determine a person's response. Greater scores of sleeping, dietary and exercising habits and smoking imply a riskier lifestyle while lower score imply a healthier lifestyle.

2. Social encounter: It provide information on an individual's social perception and social life. The recording of the reaction is analyzed. A five-point rating system is used to determine a person's response. Higher scores of social encounters imply a healthy lifestyle while lower scores of social encounters imply a riskier lifestyle.

3. Locus of control: This provides information about the person's own understanding of personal command over the disease and wellbeing. This locus of control is classified as external and internal. People with external control assume that their behavior is regulated by external factors such as chance, fate, some powerful individuals, or external circumstances. People with internal control assumes that their behavior is regulated by the factors within themselves and that events rely on their own behavior. A five-point rating system is used to determine a person's response. Higher scores imply an internal locus of control while lower scores imply an external locus of control. 


\section{PROCEDURE}

A special permission was requested to obtain the data of CVD patients from the cardiac care unit (CCU) of the hospital. The procedure began by obtaining the record of the residential address of the patients and formal permission was requested to visit these patients at home after discharge from $\mathrm{CCU}$ within 10 days to interview and finish the psychological procedure. After constituting the proper report and making clear the objectives and purpose of the study the patients of CVD collaborated willingly. All the rating scales and interview programs used for this study were handed over to each patient at their residential address. All the patients were reassured that their information would be kept confidential and would be used solely for research purposes. No time-limited was inflicted on the completion of the scales.

Instantly within a week sample of Non-CVD individuals were sort out after the medical examination by the physician who declared them normal as they were not suffering from any disease. The patients and normal were matched on one to one basis concerning their age, education, occupation, family type, and economic status. All the matched normal were given a rating scale questionnaire and were interviewed personally at their home. In the present study, the number of CVD patients was 81 , and matched nonCVD individuals were 81 so the total sample size was 162.

\section{Analysis of Data}

Data were studied with the help of statistical approach like illustrative statistics, and ' $t$ ' test.

\section{QUALITATIVE ANALYSIS}

Survey of personal data sheet was accomplished. A personal data sheet consist of 14 items was prepared. The information on personal data sheets was sought so that CVD patients and the non-CVD individual would be matched based on their age, education, family type, and economic status.

\section{Statistical Component of the Sample}

Table-1

\begin{tabular}{|c|c|c|c|}
\hline Age group & CVD Patients & Non-CVD Patients & Percentage \\
\hline $30-40$ & 12 & 12 & $15 \%$ \\
\hline $40-50$ & 41 & 41 & $51 \%$ \\
\hline $50-60$ & 28 & 28 & $34 \%$ \\
\hline
\end{tabular}

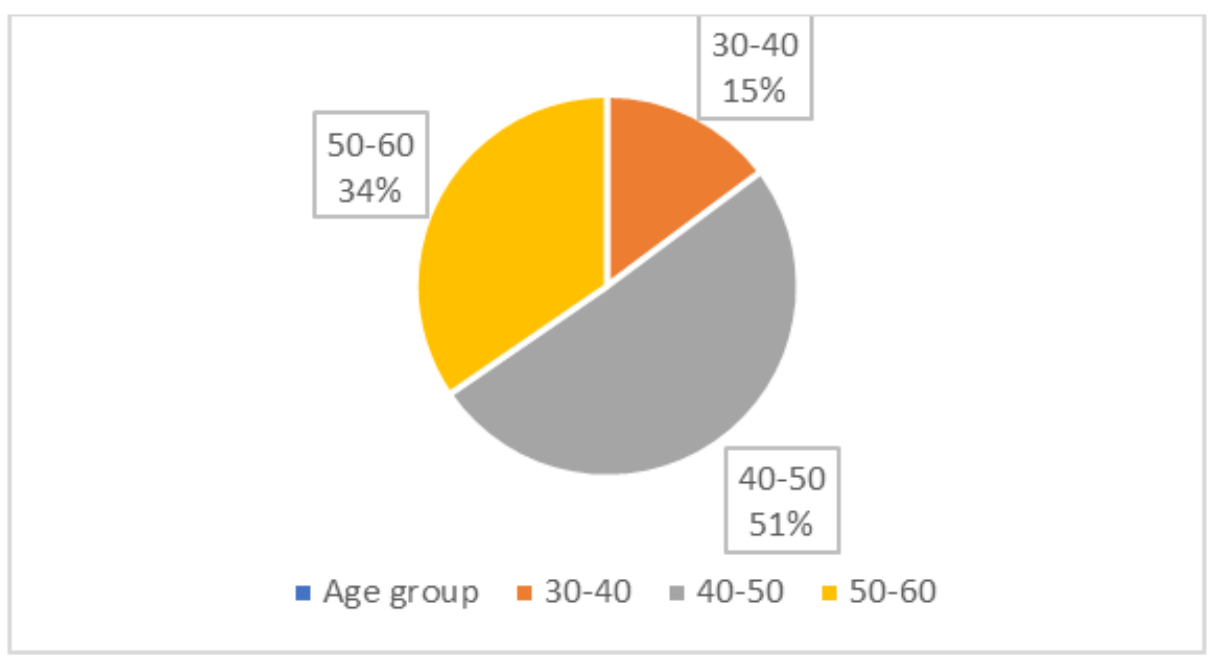

Fig-1: Sample distribution according to age $(\mathrm{N}=162)$

Representation of the Age group of the sample is displayed in Table-1 and Figure-1. $51 \%$ of the participants were in the age group between $40-50$ years.
Similarly, $15 \%$ of the participants were in the age group of $30-40$ years. And $34 \%$ were in the age group of 50 60 years.

Table-2

\begin{tabular}{|l|l|l|l|}
\hline Education & CVD patients & Non-CVD individuals & Percentage \\
\hline Diploma & 9 & 9 & $11 \%$ \\
\hline Graduate & 43 & 43 & $53 \%$ \\
\hline Postgraduate & 29 & 29 & $36 \%$ \\
\hline
\end{tabular}




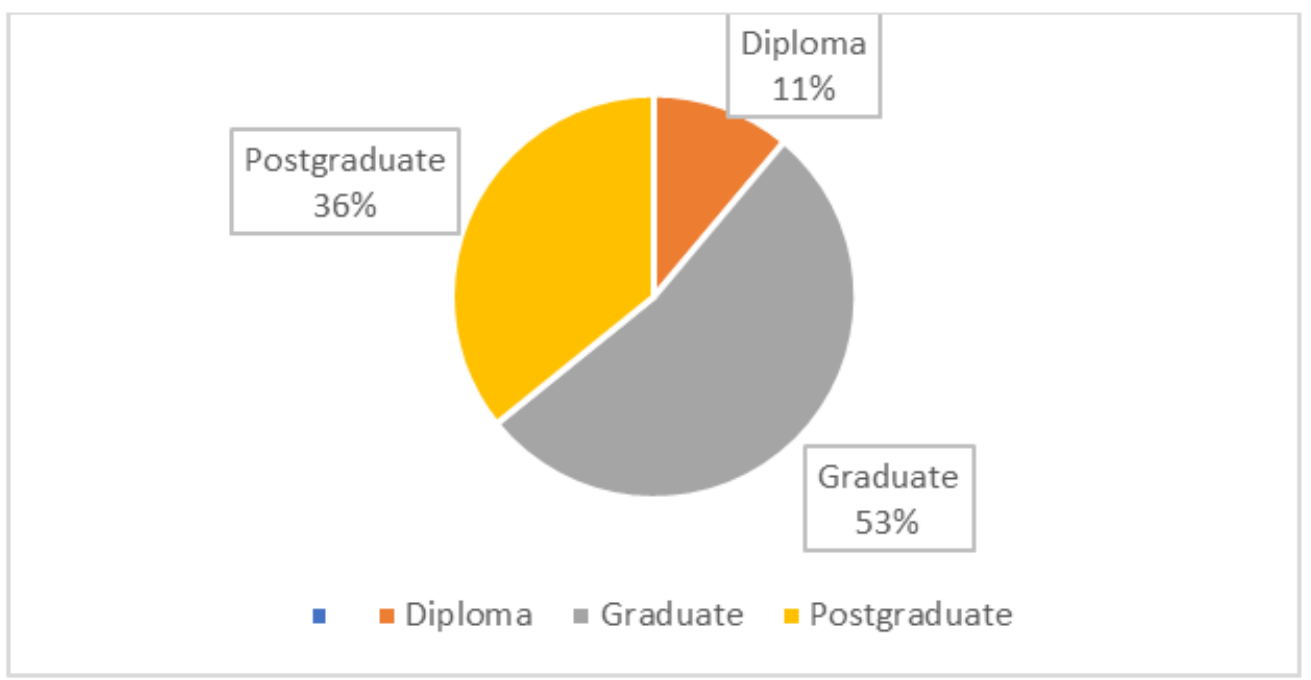

Fig-2: Sample distribution according to education $(\mathrm{N}=162)$

Representation of the education of both patients and normal individuals are displayed in Table-2 and Figure-2. $36 \%$ of the respondents have post graduate education, $53 \%$ of the respondents have graduate degree while $11 \%$ of the respondents were having diploma.

Table-3

\begin{tabular}{|l|l|l|l|}
\hline Family type & CVD Patients & Non-CVD Individuals & Percentage \\
\hline Joint Family & 23 & 23 & $28 \%$ \\
\hline Elementary family & 58 & 58 & $72 \%$ \\
\hline
\end{tabular}

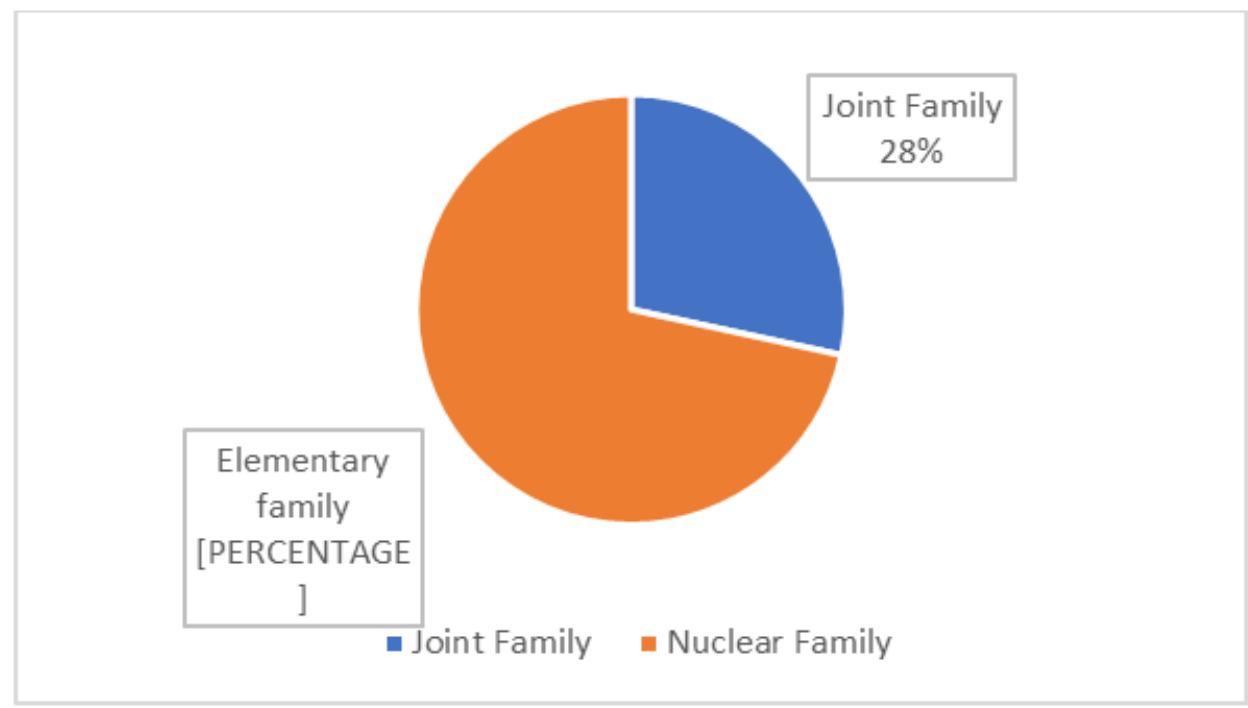

Fig-3: Sample distribution according to family type $(\mathrm{N}=162)$

Representation of the family size is displayed in Table-3 and Figure-3. It reveals that $72 \%$ of the respondents are the members of elementary family while $28 \%$ of the respondents are the members of joint family.

Table-4

\begin{tabular}{|l|c|c|c|}
\hline Annual Income & CVD patients & Non-CVD Individuals & Percentage \\
\hline $100000-300000$ & 4 & 4 & $5 \%$ \\
\hline $300000-600000$ & 31 & 31 & $38 \%$ \\
\hline $600000-900000$ & 29 & 29 & $36 \%$ \\
\hline $900000-$ above & 17 & 17 & $21 \%$ \\
\hline
\end{tabular}




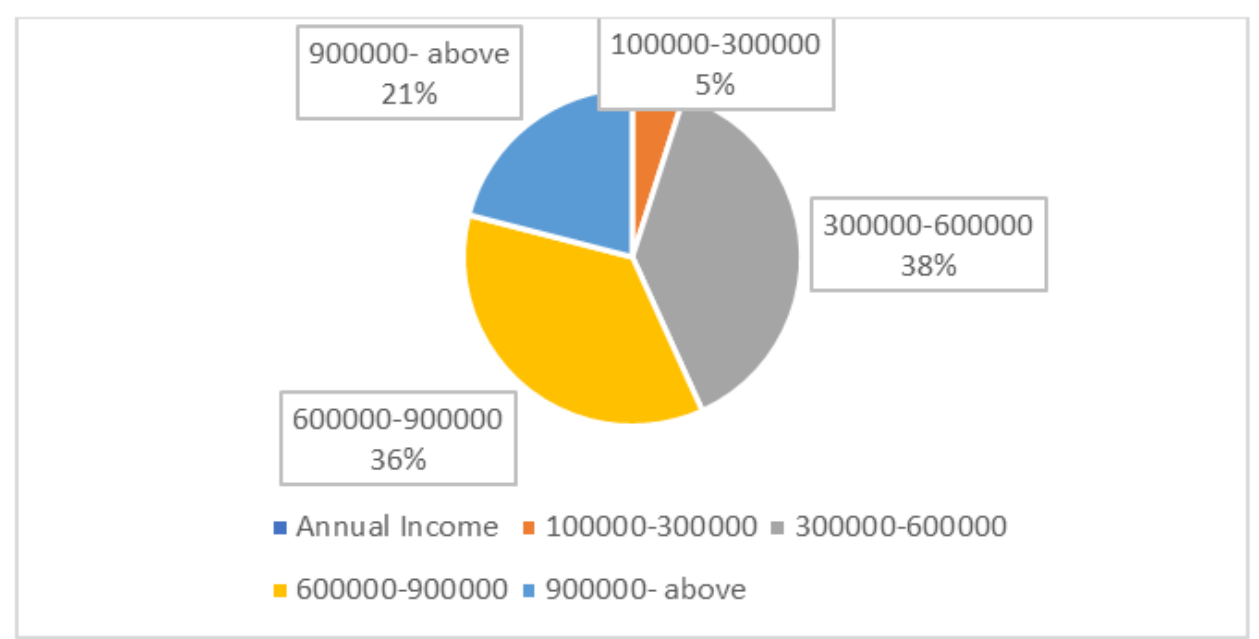

Fig-4: Sample distribution according to annual income

Representation of the economic status of the participants is displayed in Table-4 and Figure-4. It reveals that $5 \%$ of the respondents have 100,000300,000 annual income, $38 \%$ of the respondents have $300,000-600,000$ annual income, $36 \%$ of the respondents have $600,0000-900,000$ annual income while $21 \%$ of the respondents have 900,000 and above annual income.

\section{Case Studies}

We have stated two case studies to better understand in depth the experience and background of CVD patients. We can describe the lifestyle as the individual's general pattern of behavior that includes pattern of health habits, work engagement and work style, social encounter and locus of control. Health habit patterns are the series of behaviors including sleeping and eating habits, regular exercise, smoking habit, general health and emotional wellbeing

\section{Case Study 1}

A 37 years old CVD patient who has served as a senior manager for the past couple of years. He represents an elementary family consisting of a Wife and two daughters. He had no genetic history of any sort of illness. He is a non-vegetarian and majority of the time have his meal outdoors. He is a heavy smoker, work excessively for long hours, carrier oriented, selfcentered and focused on money and material possessions and spend very little time with family. A matched average person who is also a non-vegetarian but eats mostly at home with his family and very rarely eat outside. He had no bad habits like smoking or chewing tobacco. He spends most of his time with family on a weekend picnic or with friends. People are his first priority and then money.

\section{Case Study 2}

A 45 years old CVD patient who has been employed as a lecturer over the last 14 years. He has an elementary family consisting of a wife and two daughters. There is no genetic history of any sort of illness. He is a non-vegetarian and does not work out at all, he has a bad habit of chewing tobacco. He is very ambitious, but he's also found frustrated by his life and often feels sad. He doesn't spend most money on family and he's more concerned about dowry and marriage of daughters. On the other hand, a matched non-CVD individual is both vegetarian and non-vegetarian and usually walks daily for half an hour. He is a carefree guy and love all his moments and take responsibilities of his job and family

The Qualitative Analysis of these two symbolic cases of CVD and non-CVD individuals clearly signifies a marked distinction in the lifestyle variables. Now we will see the results in quantitative analysis

\section{QUANTITATIVE ANALYSIS LIFESTYLE SCORE OF CVD PATIENTS AND NON-CVD INDIVIDUALS}

In statistical analysis Mean is the average of the data set while standard deviation is the measure of variation in the data set and it tell us how spread out a group of numbers are from their means. The findings of our current study suggest that the mean differences of our data set are statistically significance as the probability ( $\mathrm{p}$ value) is less than 0.01 which means that the null hypothesis is rejected and our hypothesis i.e. "Patients of cardiovascular diseases (CVD) will have a higher lifestyle score relative to matched non CVD individuals" is strongly proved. With reference to table 5 , when the questionnaire to assess lifestyle score was evaluated it was found that the poor sleeping pattern, poor dietary intake, lack of exercise and physical activity, smoking status, low work engagement, weak social skills and external locus of control all indicate higher score of lifestyle i.e., unhealthy lifestyle and were mostly found in CVD patients. 
Table-5

\begin{tabular}{|l|l|l|l|l|l|}
\hline \multirow{2}{*}{ Lifestyle } & \multicolumn{2}{|c|}{ CVD Patients } & \multicolumn{2}{l|}{ Non-CVD individuals } & 't' ratio \\
\cline { 2 - 6 } & Mean & SD & Mean & SD & \\
\hline Sleeping pattern & 12.02 & 1.71 & 5.40 & 1.35 & 27.01 \\
\hline Dietary pattern & 22.44 & 2.20 & 9.41 & 2.16 & 37.10 \\
\hline Daily exercise & 9.42 & 1.49 & 5.16 & 1.20 & 19.90 \\
\hline Smoking habit & 26.88 & 4.50 & 13.04 & 2.14 & 24.98 \\
\hline Health & 12.40 & 2.19 & 7.64 & 1.77 & 15.15 \\
\hline Work engagement & 65.30 & 10.53 & 33.90 & 5.66 & 23.61 \\
\hline Social encounter & 62.74 & 7.92 & 26.35 & 3.88 & 37.09 \\
\hline Locus of control & 43.68 & 4.94 & 18.05 & 4.42 & 31.43 \\
\hline \multicolumn{7}{|c|}{$* \mathrm{p}<0.01$} & \\
\hline
\end{tabular}

\section{RESULT/DisSCUSSION}

The Outcome of this study confirm the previous research findings concerning lifestyle factors and the risk of cardiovascular disease. Gupta and Gupta [12] implement a study on males and in that study, it was found that lifestyle risk factors like diet, smoking habits play an important role in the development of CHD. Orth-Gomer et al., [13] have implemented that low social interaction and poor social integration anticipate the incidence of major coronary events. The results declared that the patients of CVD show a remarkable difference in the locus of control and it implies that the patients with an external locus of control experienced high stress while matched nonCVD individuals due to their internal locus of control experience less stress and hence remain healthy [14]. The findings obtained were examined in terms of the breech of the assumption and were correlated with previous research finding with required vigilance. The independent variable of cardiovascular mortality is mostly a previous family history of any cardiovascular and coronary heart diseases and mostly occurred among blood relatives. The public health agency and epidemiologist can plan and design successful lifestyle strategies for public health and behavior. Protection system should have a multi-dimensional perspective so that obligatory measure could be taken to prevent lifestyle diseases like cardiovascular diseases.

\section{LIMITATIONS}

CVD is a lifelong condition and it is hard to spot the patient as there is no obvious signs and symptoms of CVD. Furthermore, to obtain the genuine data it was the need to confer to the medical practitioner or cardiologist thus the researchers had to be entirely reliant on the data which was available in medical facilities.

As we have stated in the literature that CVD is a worldwide issue and only medical attention is given to it and we have abandoned its psychological aspect. Although there are many psychological aspects to it only lifestyle has been considered in the present research. Other dimensions also needed to be studied. This study was limited to the male population only.

\section{SugGeSTIONS}

Following are the suggestions for future researches. A comparison of urban and rural population to learn the progression of cardiovascular diseases. A similar study could be conducted on a sample of female patients and individuals.

Additional research in cardiovascular disease may implement a multi-dimensional model covering both environmental variables and social variables.

\section{REFERENCES}

1. Chockalingam A, Balaguer-Vintro I, Achutti A, De Luna AB, Chalmers J, Farinaro E, Lauzon R, Martin I, Papp J, Postiglione A, Reddy KS. The World Heart Federation's white book: impending global pandemic of cardiovascular diseases: challenges and opportunities for the prevention and control of cardiovascular diseases in developing countries and economies in transition. Canadian Journal of Cardiology. 2000;16(2):2279.

2. Atlas WG. WHO. Global atlas on cardiovascular disease prevention and control. 2011. [accessed on September 27, 2014]. Available. Retrieved from http://www.who.int/cardiovascular_diseases/public ations/atlas_cvd/en/.2011

3. Asia Pacific Cohort Studies Collaboration. Smoking, quitting, and the risk of cardiovascular disease among women and men in the Asia-Pacific region. International journal of epidemiology. 2005 Oct 1;34(5):1036-45.

4. Church TS, Levine BD, McGuire DK, LaMonte MJ, FitzGerald SJ, Cheng YJ, Kimball TE, Blair SN, Gibbons LW, Nichaman MZ. Coronary artery calcium score, risk factors, and incident coronary heart disease events. Atherosclerosis. 2007 Jan 1;190(1):224-31.

5. Kannell WB, Dawber TR, Friedman GD, Glennon WE, McNamara PM. Risk factors in coronary heart disease: Evaluation of several serum lipids as predictors of coronary heart disease: Framingham Study. Ann. Int. Med.. 1964;61:888.

6. WHO. Sodium intake for adults and children. 2014. Retrieved from 
http://www.who.int/nutrition/publications/guidelin es/sodium_intake/en/.2012

7. Rahimi K, Secknus MA, Adam M, Hayerizadeh BF, Fiedler M, Thiery J, Schuler G. Correlation of exercise capacity with high-sensitive C-reactive protein in patients with stable coronary artery disease. American heart journal. 2005 Dec 1;150(6):1282-9.

8. Kondo N, Nomura M, Nakaya Y, Ito S, Ohguro T. Association of inflammatory marker and highly sensitive C-reactive protein with aerobic exercise capacity, maximum oxygen uptake and insulin resistance in healthy middle-aged volunteers. Circulation journal. 2005;69(4):452-7.

9. Milani RV, Lavie CJ, Mehra MR. Reduction in Creactive protein through cardiac rehabilitation and exercise training. Journal of the American College of Cardiology. 2004 Mar 17;43(6):1056-61.

10. Vrijheid M, Martinez D, Manzanares S, Dadvand P, Schembari A, Rankin J, Nieuwenhuijsen M. Ambient air pollution and risk of congenital anomalies: a systematic review and meta-analysis. Environmental health perspectives. 2011 May;119(5):598-606.

11. Pekkanen J, Peters A, Hoek G, Tiittanen P, Brunekreef B, de Hartog J, Heinrich J, Ibald-Mulli A, Kreyling WG, Lanki T, Timonen KL. Particulate air pollution and risk of ST-segment depression during repeated submaximal exercise tests among subjects with coronary heart disease: the Exposure and Risk Assessment for Fine and Ultrafine Particles in Ambient Air (ULTRA) study. Circulation. 2002 Aug 20;106(8):933-8.

12. Gupta R, Gupta VP. Meta-analysis of coronary heart disease prevalence in India. 1996.

13. Orth-Gomér K, Rosengren A, Wilhelmsen L. Lack of social support and incidence of coronary heart disease in middle-aged Swedish men. Psychosomatic medicine. 1993 Jan 1;55(1):37-43.

14. Younger JB. A theory of mastery. Advances in Nursing Science. 1991 Sep 1;14(1):76-89. 